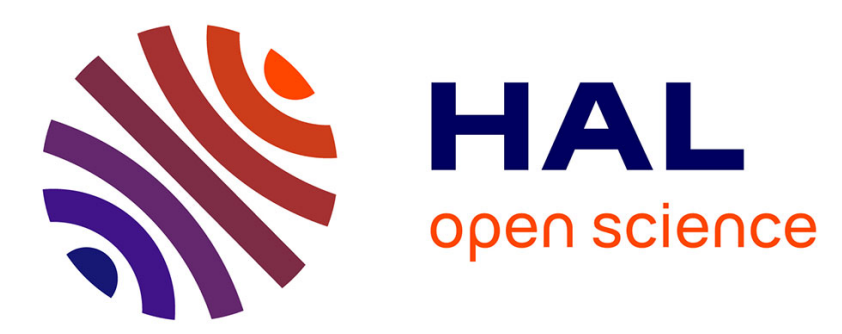

\title{
The assistant referees' activity in refereeing elite football: Preoccupations when not judging offside
} Simon Boyer, Clare Macmahon, Michel Récopé, Géraldine Rix-Lièvre

\section{To cite this version:}

Simon Boyer, Clare Macmahon, Michel Récopé, Géraldine Rix-Lièvre. The assistant referees' activity in refereeing elite football: Preoccupations when not judging offside. Psychology of Sport and Exercise, 2020, 48, pp.101662. 10.1016/j.psychsport.2020.101662 . hal-03593187

\section{HAL Id: hal-03593187 \\ https://hal.science/hal-03593187}

Submitted on 1 Mar 2022

HAL is a multi-disciplinary open access archive for the deposit and dissemination of scientific research documents, whether they are published or not. The documents may come from teaching and research institutions in France or abroad, or from public or private research centers.
L'archive ouverte pluridisciplinaire HAL, est destinée au dépôt et à la diffusion de documents scientifiques de niveau recherche, publiés ou non, émanant des établissements d'enseignement et de recherche français ou étrangers, des laboratoires publics ou privés. 
Boyer, S., MacMahon, C., Récopé, M., Rix-Lièvre, G. (2020). The assistant referees' activity in refereeing elite football: Preoccupations when not judging offside. Psychology of Sport and Exercise, 48. 〈10.1016/j.psychsport.2020.101662〉

https://www.sciencedirect.com/science/article/pii/S1469029218305028?via\%3Dihub

\title{
The assistant referees' activity in refereeing elite football:
}

\section{preoccupations when not judging offside}

\author{
Simon Boyer ${ }^{\mathrm{a}, \mathrm{c}, *}$, Clare MacMahon $^{\mathrm{b}}$, Michel Récopéc ${ }^{\mathrm{c}}$, Géraldine Rix-Lièvre ${ }^{\mathrm{a}, \mathrm{c}}$ \\ a PERF Arbitrage, Université Clermont Auvergne, France \\ b Sport and Exercise Science, La Trobe University, Australia \\ c UFR Sciences et Techniques des Activités Physiques et Sportives, Laboratoire Activité \\ Connaissance Transmission Education (ACTé, EA 4281), Université Clermont Auvergne, \\ France
}

\begin{abstract}
The purpose of this study was to elicit the activity of assistant referees during football game when they judge duels. It investigated their lived experiences, in order to understand the preoccupations they had to participate in decision making. Six professional football matches were observed and twelve self-confrontation interviews conducted. Findings showed the participation of assistant referees in decision making depends on preoccupations concerning the central referee's priority. They constructed their judgement according to the central referee's perceived contextual judgement. A latent intention to coordinate their activity with the central referee judgement is embedded in the assistant referees' preoccupations.
\end{abstract}

Keywords: decision making, contextual judgement, coordination, football refereeing, qualitative methods. 


\section{Introduction}

Most of the research about assistant referee performance has been interested in studying the judgement and decision making of offside (Catteeuw, Gilis, Wagemans, \& Helsen, 2010a, 2010b; Luis, Canelo, Domínguez, \& Morenas, 2018; Put, Baldo, Cravo, Wagemans, \& Helsen, 2013; Spitz, Put, Wagemans, Williams, \& Helsen, 2018). A number of studies make a particular point of showing the specificity of the isolated skills the assistant referees construct in the area of judging offside (Catteeuw, Helsen, Gilis, \& Wagemans, 2009; Schnyder, Koedijker, Kredel, \& Hossner, 2017). Also, the referee decisions concerning one-on-one action between opposing players on the field is often considered as an individual process better carried out by the central referee (Aragão e Pina, Passos, Araújo, and Maynard, 2018). Studies also underline that central referees are better than the assistants to meet the expert standards in the task of assessing oneon-one action between opposing players because of their domain specificity skills (Catteeuw, Helsen, Gilis, \& Wagemans, 2009; Spitz, Put, Wagemans, Williams, \& Helsen, 2018). No study takes into account the way the assistant referees' activity coordinates with the central referee concerning the similar tasks they could take in charge on the field (Aragão e Pina et al., 2018). However, there is the potential for the assistant to interfere with the central referee in the adjudication of duels.

The Laws of the Game and the official directives governing refereeing in football define the roles of each member of the refereeing team (i.e., the central and assistant referees) and the ways they collaborate with one another. The Laws of the Game state that "the referee controls the match in cooperation with his assistant referees" (IFA Board, 2012, p. 24) or with "the other match officials" (IFA Board, 2018, p. 63) notably for adjudicating duels (i.e., one-on-one actions between opposing players). According to the Laws of Game, the assistant can communicate when an offence was out of the view of the central referee and raise the flag to show that a fault occurs. Therefore, the assistant has to judge the fairness and acceptability of 
physical opposition between players as well. Thus, to more fully understand assistants' performance, research should focus on situations where they do not carry out their specific task of judging offside and rather the assistants' activity in the corresponding specific contexts of co-adjudication of game play with the central referee in order to have a better picture of their activity on the field. To understand the assistants' activity in these specific contexts, research has to take into account the more general question of non-interference of the assistants' activity in the central referee's prerogatives, which is mentioned in the Laws of the Game: "In the event of undue interference or improper conduct, the referee will relieve them of their duties and make a report to the appropriate authorities" (IFA Board, 2012, p. 28; IFA Board, 2018, p. 73). This would infer an expectation on assistants to coordinate appropriately with the referee in decision making processes as there are potential repercussions on them for improper participation. Thus, the assistants should have interest to coordinate with the referee in decision making processes, notably in the situations where each can fulfil the same tasks.

In this context, eliciting the preoccupations of the assistants could highlight the reasons for which they participate or not in decision making and how they participate. Indeed, a preoccupation conveys an interest in relation to what is meaningful for the teammate in situation (Bourbousson, Poizat, Saury, \& Sève, 2011b). The preoccupations of a teammate delimit his/her activity in situation. Therefore, the way the assistants make their decision could depend on the way they are preoccupied by the central referee's decision making processes. In order to highlight the coordination in sport teams, phenomenological psychology studied preoccupations (or concerns) of the team members and provided insights into the way the activity of sport team members fits with the activities of their teammates within the team's activity. Bourbousson, Poizat, Saury, and Sève (2012) indicated that in a homogenous team the instances when teammates shared the same typical preoccupations were relatively rare. Rather, for the most part, each teammate has their own preoccupations, but this does not impede to 
share also similar preoccupations or compatible preoccupations with one another (Bourbousson, Poizat, Saury, \& Sève, 2011a; 2012). Thus, the present study is based on the first hypothesis that the assistants should have specific preoccupations in terms of coordinating their activity with the central referee. However, studying their preoccupations entails identifying which contextual information they take into account specifically in order to intervene in the adjudication of duels (Poizat, Bourbousson, Saury, \& Sève, 2009).

In refereeing, Mascarenhas, Collins, and Mortimer (2005) have underlined elite rugby referees decision making. More research is needed that takes into account the notion of contextual judgement in refereeing performance as Mascarenhas and colleagues originally suggested. These authors showed in half of decision incidents in rugby, central referees and linesmen disagree with expert judgements. Rather, they make decisions according to their contextual judgement which is based on a hierarchical weighting scale of discretionary values and their relationship to the game (Mascarenhas, Collins, \& Mortimer, 2005). The authors suggested that the contextual judgement is based on the way officials perceive the context of the match and its course at the moment the decision is made. Therefore, studying the preoccupations of the assistants entails studying if their potential preoccupations about the central referee's activity lead them to take into account contextual information which could shape their contextual judgement. As a consequence, the present study is based on a second hypothesis that to understand the activity of assistant referees in football, the understanding of contextual judgement should be a key feature. It aims to explore the contextual judgement of assistants and the manner in which their consistency is constructed. The researchers also remain aware that to study the construction of contextual judgement for the assistants, the potential calibration of the referee judgement in the beginning of a match should be considered (Unkelbach \& Memmert, 2008). Thus, this work takes into consideration this topic by questioning the possibility that an assistant should calibrate his/her judgement during a football 
match concerning these physical oppositions too. But if previous research has highlighted the way referee judgement can be biased by contextual information (Plessner \& Haar, 2006), rather this research constitutes a first attempt in order to improve understanding of assistant referees' contextual judgement from a non-normative point of view (Russell, Renshaw, \& Davids, 2019). Particularly, it aims to carry out contextual information assistant referees take into account to judge and decide in naturalistic situations.

Studying assistant referees' preoccupations and contextual judgement during a match should help to understand their activity when they do not judge offside. Besides, highlighting how they contribute to refereeing duels can be a base for formulating proposals to improve performance inside the collective refereeing group, particularly when this means achieving greater consistency between the judgements of the team members concerning the refereeing of duels. Thus, this study responds to a need for research to better understand the performance activity of assistants in refereeing, when adjudicating duels. This can be achieved through investigating the potential link between the assistants' preoccupations concerning coordination with the central referee activity and their contextual judgement in matches.

To fulfil this research objective, the subjective and discretionary points of view of assistant referees in situ will be analysed. Phenomenological psychology provides conceptual tools for this type of approach, through a constructivist framework, to help understand cognitive processes of individuals as embed in the context in which they take place (Theureau, 1992). This approach enables the reconstruction of meaningful performance experiences for the actors. Empirical studies using a phenomenological approach have made a point of showing that what is significant for the referee is constructed progressively in the flow of his/her course of experience relating to his/her perception of the players' activity (Rix, 2005). The purpose of this study is to explore the lived experience of high performing assistant referees in order to clarify their preoccupations and contextual judgement in the refereeing of game. The 
anticipated findings will characterise the significations of their experiences when they either participate or do not participate in the refereeing decisions concerning duels in a match.

\section{Methods}

This research adopts a phenomenological psychology methodological framework to study significant elements of the assistant referee's lived experience on the field (Theureau, 2003, 1992). Particularly, self-confrontation interviews provide the opportunity to make certain aspects of the participant's experience, still implicit in the situation, updated and explicit. The subject can partly describe reflective and pre-reflective levels of their experience, as lived in the first person in a singular situation (Gouju, Vermersch, \& Bouthier, 2007; Poizat, Bourbousson, Saury, \& Sève, 2012; Vermersch, 1999).

Interviews consisted of confronting an individual about his/her behaviour in a particular situation through the use of video exposure: he/she views a physical record of his/her acts in a specific context. Once the participant identifies a part of his/her behaviour to highlight, the video is stopped. Video is used to prime the description of his/her experience. By initiating and guiding the effort of reflection, the video constitutes a support for the individual to go back over the experience - a return towards a past experienced situation. Reference to the video recording as a trace of activity is also a means of framing the participant's discourse and acts as a reference for subsequent verbalisations. Specific interviews techniques are used to make the participant describe and explicate what is significant for him/her, at that time in situ (Rix-Lièvre \& Lièvre, 2009; Vermersch, 1999). The interview brings the participant to introspection to elicit his/her experience and to guide him/her to deeper and descriptive details. During the self-confrontation interview the participant describes to the researcher the course of his/her actions by making the moment, as experienced, more intelligible (Theureau, 1992, 2003). 
This method produces an empirical phenomenology of human activity (Theureau, 2003). The participant does not have direct access to the meaning of their experience as it is not "immediately accessible to him, for it is broadly implicit in the meaning of the pre-reflective" (Vermersch, 1999, p. 13). The researcher helps the participant to formulate and make explicit what mattered most for him or her in the situation (Poizat, Sève, \& Saury, 2013; Vermersch, 1999). In order to make participants eliciting subjective experience on the field, the guidelines of self-confrontation interviews require one to construct a global understanding of the sociocultural framework before the investigation of the activity (Theureau, 2003). Thus, the interviews were part of a broader protocol. To construct this global understanding, the researcher used an ethnographic approach of participatory observation.

\subsection{Participants}

12 elite male, national and professional level assistant referees from the two highest national levels of the French professional championship (one in Ligue 1 and five in Ligue 2) were involved in the research. Six football matches were investigated in total during the 2012/13 and 2013/14 seasons. Each match studied was not decisive for the ranking of the championship season; i.e. the opposing teams were not closed together in the ranking.

The participants were aged between 31 and 38 years old at the time of the study $(\mathrm{M}=$ $34.75, \mathrm{SD}=7.1$ ). The number of years of experience in refereeing at professional championship is between 1 and 7 years $(\mathrm{M}=4.75, \mathrm{SD}=3.3)$. Seven of the 12 participants have experiences in the refereeing of matches during international competitions; none of them was a FIFA assistant referee.

\subsection{Procedures}


Phase 1. To have access to the pitch and ask the referees for an interview each investigation was authorised by the Direction Technique de l'Arbitrage (Refereeing Technical Board of the French Federation of Football). Before the day of the match being studied, the overall research objectives, and procedures were presented to the members of the officiating team. The procedures were approved by the Ethics Review Board of the University, and each official who participated in the study provided informed consent. For each match we obtained the video of the game from the Ligue de Football Professionnel (LFP - Professional Football League). These video recordings give a wide angle view from the stands - with close-ups on certain events in the game.

Phase 2. On the day of the match the researcher (first author) joined the officials' team during the pre-match preparatory work as a participating observer. To join the group as an observer, the researcher committed to respect the instructions the central referee gives to him in order to not disturb the team work notably during the pre-match briefing. The information being discussed was, e.g., the characterization of the duels they could have to adjudicate. During the observation, his posture was to comply with the hierarchal organization of the team and the social codes and uses of the refereeing community. The researcher produced two types of ethnographic notes as part of the data collection: (a) ethnographic notes taken from the gathering of the officials before and after the match until the departure from the stadium, and (b) notes about the events in the match which could not appear on the video screen during the interview because of camera angles. These observations provided supplementary information about factual elements concerning the officials' and players' actions which could be important to help the officials to elicit their experiences. To create event notes and complete the descriptions during the game from the stands, we have identified the ostensible decisions factual events expressed through actions that are codified in regulations as signals or whistles - and the visible interaction between officials. 
Participatory observation conducted by the researcher during the entirety of the match day required a progressive integration inside the refereeing community by taking part in training sessions, attending matches and meetings, or by meeting referees and managers of refereeing. This occurred formally or informally. The researcher had been regularly involved in the refereeing community during two years formerly to this study. This 'embedding' allowed a first level understanding of the assistants' activity. Moreover, an implication of the participatory observation is that the researcher adopted the posture of a naive person wanting to learn from the actors with a comprehensive attitude. This non-judgemental posture fostered each official to give an account in the interview of what he experiences in a match.

\subsection{Interviews}

Twelve individual self-confrontation interviews were carried out with the twelve assistant referees after their match. Each self-confrontation interview was carried out as soon as possible in the five following days after the end of the meeting and before another match was refereed. The individual self-confrontation interviews were carried out successively by the same researcher (first author), and were all filmed. The interviews took place in a private setting where no distraction for the participant and for the interviewer could occur (generally, at the referees' home). The camera filming the interviews centred on and captured the computer screen that the researcher and the interviewee watched. This computer screen displayed the images of the match which the assistant referee officiated.

\subsection{Types of constructed data}

First person data. The main research data constructed for each investigation were each assistant referee's verbalisations during the self-confrontation interview. The participants' confrontation with the factual events of their activity on the video allowed them to structure the 
verbalisation of their experience after the event. The verbalisations produced by the interviewee in interview came from a reflection that reveals the significance of events in the subject's experience. Thus, it also has to be considered that the assistants' in-match activity and the verbalisation of their experiences belong to different time-frames. The effort of reflection and making experiences explicit is situated. In other words, the meanings of the experience are constructed in a specific manner according to the conditions in the interview, in interaction with how they were controlled by the researcher/interviewer. The self-confrontation is an interlocution (Theureau, 2010). During the interview, the possibility of describing experience in detail during high-level football matches was based on the way in which the relationship between the researcher and the participant has been built. Therefore, the preparation of the interview situation was crucial, generating meaning from what was experienced during the events in situ. For the participant, talking about his/her experience entails his/her adoption of a collaborative approach characterised by the sincerity of his/her account. To achieve this collaboration, the researcher had to successfully gain the interviewee's confidence. The researcher had to show empathy and appear sincere towards the participant without seeking to test the truth of what the participant shares. The participatory observation with the refereeing team enabled to create rapport and confidence with each participant. In order to construct the optimal conditions for conducting the interview, the researcher adopted a reflective approach to suspend his/her judgement and control his/her preconceptions (Theureau, 2010, 2003). This process of reflecting on one's own categories of thought helped maintain a vigilance to eliminate preconceived notions about the outcomes of the research and about the interviewee and his/her activity (Rix-Lièvre, 2010).

The description of the participant's experience entailed having put him/her back in the context of the match as it progressed. To achieve this, every interview started by asking the participant to describe the circumstances of the pre-match. This priming was chiefly achieved 
by showing participants pre-match images, which was used to facilitate the actor's/actress's reimmersion in a past situation, placing him/her back in context to assist him/her in providing the reasons for his/her actions (Vermersch, 1999). Asking each participant to share his/her words, signs, or looks exchanged with other referees during the match was also used as an aid in conducting the interviews. To buttress the confidence between participants and the researcher, the latter demonstrated that he keeps what the interviewees say confidential (Dale, 1996, 2000). Accordingly, the interviews were conducted independently of one another: the content of one was not mentioned while conducting another, even within the same team.

Third-person data. Third-person data were also constructed (Poizat et al., 2013). Thirdperson data was represented in the descriptions of the in-match play contexts: from the researcher's observations during the match and from viewing videos. These descriptions were timed within the interviews; they concern the facts with which the officials will be confronted when viewing the video of their match and on which they primed the description of their experience. For each of the episodes that the participants experienced and described, an extrinsic observation was produced. These factual observations included the identifying number of the match studied and markers in time and space to situate the events in the course of the match - the actions of play of the players and officials.

\subsection{Processing of the data}

The first phase of processing the data involved a pre-shaping of the body of first and thirdperson data. Indeed, the use of these two kinds of data within the analysis enabled greater detail to be given to the description of assistants' situation. In that, it enables the articulation of contextual information on which they were focused on and the contextual conditions under which such cues were perceived (Poizat et al., 2012). Each interview (recorded by video) was transcribed and synchronised with the descriptions of the video images of the matches. This 
synchronisation of the first and third-person data matches the experience described by the participants and the corresponding facts. This arrangement of the data into first-person and third-person are presented in Figures 1, 2 and 3.

In a second phase, the purpose of the processing of the data was to identify the meanings of the experience the officials made. The work consisted of avoiding misunderstandings by the researcher about the experience described or over-interpretations induced by the themes of the research (Dale, 1996). For this purpose, the researcher complied with the demands for interpreting and analysing data constructed for phenomenological research by carrying out a work of phenomenological reduction. Processing stages were rigorously observed through several steps: (a) a group of researchers specialised in qualitative research has been used to process the synchronised data in table form (see Figures 1, 2 and 3). The researcher directing the study made sure that officials remained anonymous by using pseudonyms for other participants; (b) the researchers read the tables of synchronised data several times to formalise the in-match experience, the interviewee's exact words were read to the research group by the principal researcher conducting the interviews, the changes of tone and signals of affect were noted and revised in the transcriptions; (c) the researcher group, together, then compared their individual interpretations of the verbatim accounts; this provided the opportunity for the interviewer to share how he had grasped the meanings the official shared with him/her during the interview; (d) a hermeneutic procedure was adopted to interpret all the tables of a match. This consisted of a process of linking the meanings of the first in-match experiences described to the meaning of the ensuing experiences. To exemplify, pairing referees' experience of an argued call with the experience of hearing comments by a player; the experience was lived as a series of meanings constructed about factual events which were created for a subject. Thus, similarities in the various experiences the referees encounter were identified during various match events and in every case they were referred to by returning to the verbatim accounts in 
their entirety; this process made it possible to determine the commonality of events and if singular, specific meanings and experiences emerged; to ensure the data's validity, three of the authors participated in the interpretation of the tables; the tables were shared in the group to be discussed and debated; (e) an idiographic and nomothetic interpretation of all the tables was produced; the idiographic description consisted of interpreting the tables of each interview as a case study; the nomothetic description consisted of interpreting each interview in relation to all the other interviews. The researcher's intention was not to generalise the interpretation but it was a question of determining how one experience resembled another and bringing out the rationalities that organised the assistants' experiences; (f) in order to specify the processes of their activity, the idiographic and nomothetic descriptions were created following an iterative approach in order to reach more general dimensions of the experience; every divergence in the descriptions was discussed by the authors until an agreement was reached. A total of three hundred and twenty tables were analysed covering all of the matches studied. In phenomenological research a study is not fully valid if it lacks a first-person description of the phenomena. Methodological approach previously discussed aimed to approach the assistants' experiences in match situations. The use of three experienced researchers in order to triangulate and query the interpretations of the researcher who conducted the interviews enables the validity of the interpretation work of the researcher.

\section{Results}

The processing of interview data resulted in three emergent categories of the assistant referees' participation or non participation in the decision process, these included "non-participation of the assistant referees in decision process related to the priority of the central referee"; "participation of the assistant referees in decision making related to the absence of central 
referee's decision process and appraisal" and "consideration of the central referee's judgement”. Each of these are explained and supported by interview excerpts below.

3.1. Non-participation of the assistant referees in decision process related to the priority of the central referee

When a duel seems unacceptable to the assistant referees, their intervention does not occurs systematically. In the experiences described, the non-interventions of the assistants in the refereeing of duels are related to their perception of the central referee's decision-making. The example in Figure 1 shows that, for the assistant, a decision has to be made ostensibly; however, he does not intervene in the making of the decision. 
Match 2 / event 9 / 9min50s

Extrinsic observation: After a duel close to the touch-line of assistant referee 1, the red wing defender (dark in the image, red goal in the image) makes a pass forwards towards the red left-half. During the pass a white player runs at right-angles to the ball's trajectory to intercept the pass. In the duel zone (see Figure 1) the red midfielder controls the ball and directs it forwards. At the same time the white player tackles to recover the ball. A contact between the players takes place. The red player keeps the ball, then hops and falls down. The central referee whistles. Play stops. The central referee signals a free kick is awarded to the red team.

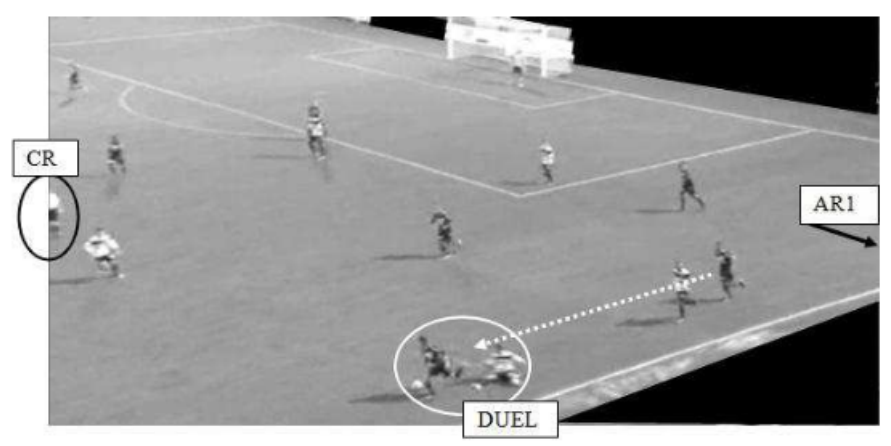

Picture of match 2, event 9

AR1- He's seen the foul [the central referee], because in the earphone (...)[1]

AR1- At first he'd let the play go on, and then afterwards he comes back to the foul, in fact. He's allowed himself the time to see what the tackle was like. [2]

RS- That's what you're telling yourself then?

AR1- Yeah.

RS- You tell yourself... (...) And you feel... No, but the...

AR1- And he whistles.

RS- ... the time lag you...

AR1- Yeah. And... he...

RS- You... you sense him?

AR1- No, but I hear him. And I hear him, that he says "Play" and that he comes back to the foul. [3]

AR1- So ... that's why I don't raise. [4]

RS - There, you didn't raise for the foul [with his flag].

AR1- No. No, because for me he can see it, so there's no point. I'm not about to raise it when he sees it. [5]

Fig. 1. Example of description of lived experience concerning non-participation in decision process related to the priority of the central referee.

Note. The number of match studied (for example in Fig. 1, Match 2), the number of the event studied in the course of this match (for example in Fig. 1, Event 9), and the timing of the event in the course of this match (for example in Fig. 1, 9min50s) are men- tioned in head. In the verbatim column the letters CR mean Central Referee, the letters AR1 mean Assistant Referee number one, the letters AR2 mean Assistant Referee number 2 and the letters RS mean Searcher. The assistant referee number one is the one who takes place along the touch-line in front of the substitutes' bench. The assistant referee number two is the one who takes place along the touch-line on the opposite side of the one of substitutes' bench. The picture in each figure represents a frozen image of the video used to conduct the selfconfrontation interview. The capture is taken at the moment of the assistant re- feree's verbalisation about the event represented on the video screen during the interview. 
Interpretation of quote [1]. The assistant referee appraises a player's behaviour as being unacceptable: for him play could be stopped by the central referee's whistle (as finally happened in the example). Unacceptable means not legal related to the context of the event. The assistant perceived at the same time a non-codified behaviour of the central referee's, an audio communication, showing that the central referee has seen the foul. Implicitly, this means that the central referee could also show that the game can go on by signalling the foul and the application of the advantage rule. In spite of this, the assistant does not take part in refereeing by signalling or making any indication by radio communication.

Interpretation of quote [2]. For the assistant referee, his perception of non-codified forms of behaviour in the earphones means that a decision process in progress. The assistant referee gathering that the central referee is in the process of decision-making means that the actions and their unacceptable nature have been perceived. Such as the time-lag in the central referee's decision-making, enables him to determine what is happening in this process for the central referee to complete his decision concerning the unacceptable tackle.

Interpretation of quote [3]. The assistant clarifies his perception of a non-codified form of behaviour, the utterance "play", between the physical contact and the whistling: the result of the decision process should be that the game can go or stopped by signalling the foul. This quote confirms the interpretation of quote 2 and 3. But finally, the central does not let the game play because the unacceptable nature of tackle does not allow the game to go on. The assistant confirms that he has correctly discerned that the referee had been processing the action and given himself the time to complete his decision.

Interpretation of quote [4]. The assistant tells that the reasons why he didn't raise the flag to signal the foul are (1) that the central referee is processing a decision and (2) that finally 
he has completed his decision. Implicitly he signifies that his own decision to raise the flag or not is subordinated to the central referee's perception and judgement.

Interpretation of quote [5]. By this sentence, the assistant referee validates the subordination of his own activity to the central one. The assistant referee considers the central referee's activity to have priority to complete the decision.

Our processing of research materials shows that in these cases - cases where according to assistant referees a decision has to be made by the central referee - the assistants first see the central referee's decision-making activity as the exercise of a discretionary and priority judgement - they do not intervene immediately. The assistants then put their own judgement in perspective. They are doing this in relation to the central referee's judgement; the assistant referee's judgement is here subordinate to that of the central referee. This subordination rests on the recognition of the central referee's superior hierarchical status and greater responsibility for the course of the game. The central referee's decision process is perceived as a higher priority and this perception means that the assistant referees actually subordinate their activity to the central referee by not intervening in the refereeing.

\subsection{Participation of the assistant referees in decision making related to the absence of central} referee's decision process

The cases of instances of players' behaviour that the assistant referee appraises to be unacceptable and where he identifies no decision process is taking place by the central referee illustrate the way in which the assistants' activity is subordinated to the central referee's. The example in Figure 2 lets us specify how the assistant's activity is put in perspective and subordinated to the central referee's when the assistant determines that the central referee is not engaging in a decision process. 


\begin{abstract}
Match 2/ event 48/ 61min20s
Extrinsic observation: In his run the red team right winger (dark stripe on the screen) receives a high pass from behind him. The ball falls in front of him. A white team defender (light stripe on the screen) comes between him and the goal. The red striker hits the ball on the volley with the outside of the left foot: the ball does a bell curve above the white defender. The white player makes contact with the ball (see Figure 2). Assistant referee 1 raises his flag; he signals a foul by the white defender. The central referee whistles; the game stops. He signals a free kick in favour of the red team.
\end{abstract}

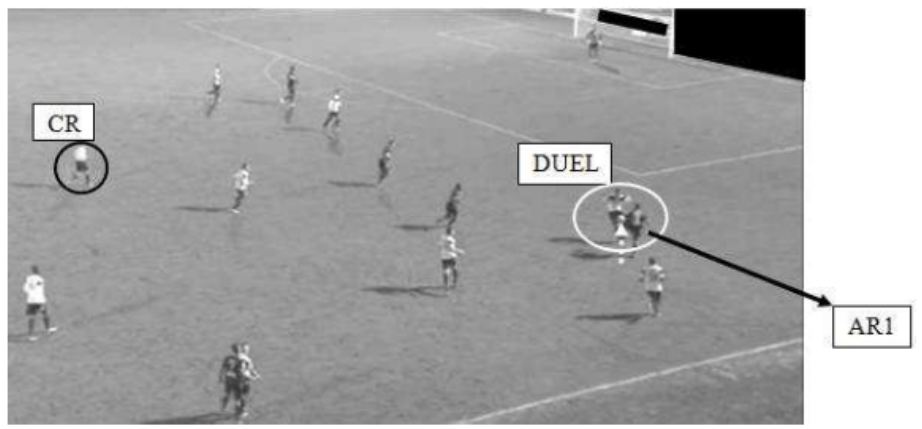

Picture of match 2, event 48

AR1- Ah there, there's a foul.

\title{
Verbatim AR1
}

AR1- Yes. (...) Well there's... Anyway, I signal the hand-ball.

RS- You signal the hand-ball?

AR1- Yes, because I... For me there's hand-ball. (...) [1]

AR1- And CR can't see it. [2]

AR1- CR is very far... (...) so er...It's part of a, a useful signalling, you see. (...) Useful, that's it. I.e. he doesn't see it... [3]

RS- I.e. you take.

AR1- That's it, I take, that's it... (...) More than the question of the zone, there's his position... (...) and he's too far. Too far. (...)

He was too far. (...) So that's part of the necessary ... decisions. That's all. [4]

Fig. 2. Example of description of lived experience concerning participation in decision making related to the absence of a central referee decision process.

Interpretation of the quote [1]. The assistant referee appraises the unacceptable nature of the players' behaviour.

Interpretation of the quote [2]. The assistant grasps that the central referee has not been able to see the unacceptable behaviour. Tacitly, at this moment, it means that an obstruction of his vision by the players or a too long distance of the central referee from the action to well see it. 
Interpretation of the quote [3]. The assistant is more precise concerning the description of his perception of the referee situation, notably his position in relation to the players and the ball. The distance between the central referee and the game being too important: which implies he cannot see the players' behaviour and the action around the players' position. For him, he made a useful decision by signalling the hand-ball.

Interpretation of the quote [4]. The assistant referee tells that the reason why he signals the fault: he made the decision not because the foul occurs in a pre-established zone of responsibility, he did not follow a pre-established plan. He makes the decision because he identifies the central referee cannot see the action.

That the central referee cannot see the action of play implies that no decision process concerning the players' unacceptable behaviour can be effective for the central referee. In this way the assistant identifies that his own participation in the decision process is possible; so once again his activity is subordinated to the central referee's. The central referee's absence from the decision process concerning the players' unacceptable behaviour constitutes an opportunity for the assistant referee to intervene. If the central referee's non-intervention, perceived by the assistant referees, is not accompanied by the perception of the occurrence of a decision process by the central referee, the central referee's non-intervention constitutes an absence of decisionmaking and an opportunity to intervene in the refereeing for the assistants. The assessment of the central referee's situation is what determines whether the assistants' intervention in the decision process is opportune from the assistant's point of view, and, when necessary, whether intervention is necessary (the decision may be that a no-call is appropriate and thus no intervention in the refereeing is called for).

\subsection{Appraisal and consideration of the central referee's judgement}


While the assistants' participation in the refereeing is conditional on the opportunity to intervene, the data processing shows the assistants' actual participation (or non-participation) is organised in relation to their appraisal of the central referee's judgement. Assistants take the previous judgements of the central referee into account in deciding whether they should intervene or not in the play - as shown in the example presented in Figure 3.

\begin{abstract}
Match 4/ event 52/ 34min26s
Extrinsic observation: After a long throw-in by the blue right back from centre field towards the yellow goal (left of the images) and towards his blue right-half partner, the ball is intercepted by the yellow left-half's header. The ball fall back towards the blue right winger who controls with his chest with his back to the goal by placing his body in opposition between the ball and the yellow central defender behind him. A contact takes place between the two players, the blue winger falls down. The ball comes back to the feet of the yellow players (see Figure 3). The referee signals with his hand there's no foul and play continues. The play restarts towards the blue goal.
\end{abstract}

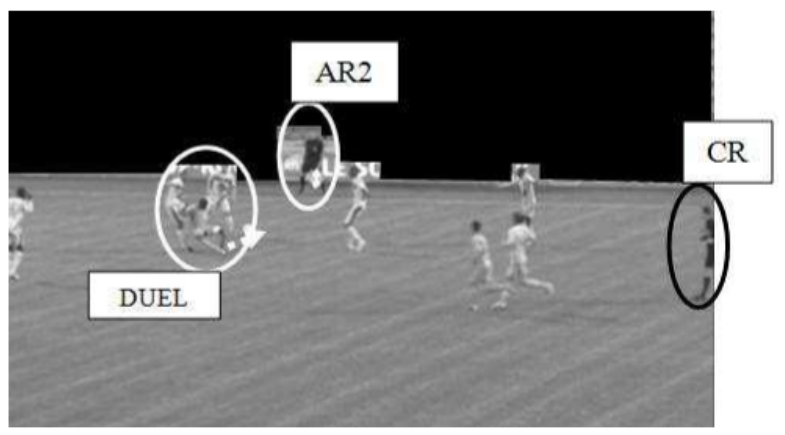

Picture of match 4, event 52

AR2- So you can consider when you look that actually the yellow can hold a little bit the ... (...) ... the blue, and then you saw the blue who goes back a little bit too. (...) Who goes back and who goes back not to fall backwards because... (...) ... he's unbalanced. [1]

RS- You look at that, do you?

AR2- Yes, we look at that. Er, so there, at that spot on the pitch, I want to say about twentyfive metres from the goals, if I signal there, I think l'll force CR to signal... to whistle when he won't want to... (...)

In relation to the tolerance threshold he's put for the fouls. [2]

RS- OK.- as a result - you've seen it on other er...

AR2- Well, it isn't even part of the tolerance threshold, in general, l'd say even about what I think ... (...) l'd say it's little tugs on shirts, ... [3]

Fig. 3. Example of description of lived experience concerning appraisal and taking into consideration the central referee's judgment. 
Interpretation of quote [1]. The assistant referee appraises the acceptable character of the players' behaviour (i.e., legal or not in the context of the event). He described the criteria he used in situation to make his decision determining the player's behaviour as acceptable.

Interpretation of quote [2]. He puts his own judgement in perspective relative to the central referee's. He compares the central referee's judgement with his own if he should signal a foul in this context -" 25 meters from the goal". He also appraises the central referee's judgement when the latter does not intervene in the play concerning similar duels during the match (see verbatim [4], Figure 3). To describe his appraisal of the previous judgements of the central referee, the assistant used the terms "tolerance threshold".

Interpretation of quote [3]. Thus the assistant referee describes his own judgement by comparing it and referring it to the central referee's. It confirms the previous interpretation.

During the game the assistant referee notes the type of play that the central referee helps create with the players through his refereeing interventions. He determines the type of play that results from the central referee's decision and the players' behaviour. In this way the assistant comes to understand how to bring his present judgements, and those to come, into line with the central referee's by giving himself the possibility of adjusting his judgement of duels to how the central referee judges them. The assistant referee carries out a sort of updating of his judgement with the central referee's.

\subsection{Analysis of the preoccupations and cues}

As the three examples illustrate, the assistant referees' understanding of the action and decisions in duels showed that they are preoccupied by whether the players' behaviour is acceptable or not. But, prior to any intervention in the refereeing of these duels, the assistant referees pick up meaningful cues (auditory and visual) in the activity of the central referee that provide indications to understand the decision-making process of the later. To understand the 
central referee's decision process, the assistants refer to various types of cues like the central referee's spatial markers of orientation in relation to the play (distance from the players, orientation to the field, body orientation - even the direction he is facing -, players between the referee and the ball), or observable instances of behaviour, verbal or non-verbal (movement of the whistle from the hand to the mouth, how the referee stands). When the assistants determine that the central referee's non-intervention in the play (as an absence of stoppage of play) is a decision process, they do not intervene in the refereeing and make no indication or signal. This appraisal makes it possible to determine whether an intervention is appropriate. To sum up, in situ, the assistants' intervention in refereeing duels is dependent on their understanding of the situation according to two preoccupations: on the one hand, relating to the players' activity by determining whether their behaviour is acceptable or not, on the other, relating to the occurrence of a decision process by the central referee.

For the assistant referees, the cues that indicate a decision process is taking place for the central referee also indicate a priority of the later in the refereeing. However, the principle of priority is not clearly made explicit in the interviews. When perceived, the cues of a decision process implicitly signify the subordination of the assistants' activity to the central referee's. They do not make this knowledge relating to the priority explicit. The significant cues of the central referee's situation are not the subject of a debate in situ. In themselves, the cues for the assistant referees convey detailed and updated knowledge about the collective organization or about common social practice within the refereeing team that takes place in a given context.

The interviews with assistants revealed that the preoccupation with the priority of the central referee's decision process becomes more complex when the potential intervention by assistant referees is at issue. Throughout the match, the assistant referees reach an understanding of the circumstances of the central referee's decision-making in the cases of duels when the central referee intervenes in the course of play. They identify the type of context 
relating to the players' activity and about which the central referee makes the decision. The assistants do not just understand the occurrence of a decision process; in this case they also grasp the meaning of the intention of the central referee's intervention related to the creation of the game. For this, they refer to verbal (central referee thinking out loud, verbalisations to the players) or non-verbal behavioural cues (ostensible signals). Thus, the assistants in situ reach an understanding of the conditions in which a central referee considers a duel as acceptable or not. Whether the central referee halts play, or shows an advantage, or indicates to the player that they should play on or again simply lets the game continue, through understanding the players' activity resulting from this decision, the assistants grasp the nature of the play it helps produce. In this way over the course of the match the assistants construct categories from the physical contacts qualified as acceptable or unacceptable by the central referee. These categories enable the assistants to identify what should be considered acceptable (or not) for the rest of the match. The construction of these categories showed that the preoccupation of the assistants concerning the central referee's decision process is shaped by a latent intention to make their judgement consistent with his own one.

\section{Discussion}

The purpose of this study was to understand the activity of high performing assistant referees in football by identifying their preoccupations during the moments they do not judge offside. Our findings about the three categories of meanings the assistants lived - nonparticipation in decision process related to the priority of the central referee; participation in decision making related to the absence of central referee's decision process; appraisal and consideration of the central referee's judgement - provide insight into their preoccupations.

The assistants have preoccupations with the central referee's priority to intervene in the course of the play; they appraise whether there is a decision process happening with $\mathrm{him} / \mathrm{her}$. 
Thus, if the issue of assistants' performance in offside judgement area excites strong scientific interest (Aragão e Pina et al., 2018) the findings of this study show that intervention in refereeing duels is the subject of preoccupations for them also. This emphasises that to fully understand the activity of assistants, point of view beyond understanding the performance of the specific tasks in the role is needed that considers it as a whole, as part of a refereeing unit with superordinate and subordinate responsibilities. Further, assistants' activity cannot be understood without considering how they come to understand the central referee's activity.

The data analysis showed that the way assistants participate in decision making reveals that the assistants adjust their way of judging duels to how the central referee judges them. According to Mascarenhas et al. (2005), contextual judgement presents degrees of freedom that are often too complicated to explain. They hypothesise contextual judgement works following a hierarchy of values for the various signals and scales of values for the individuals that vary depending on their personal history. Our results show that the recognition of a foul and of its importance in a match depends on the relation they have constructed with the game in the unfolding of the context of the particular match. The findings of this study show that the assistants' judgement is referenced to the central referee's activity and this referencing takes the dynamic of latter judgement into consideration and its evolution during the match (based on its contextual character). Assistant referees' judgement of one-on-one duels arises from a construction developed as the match progresses. They construct categories consistent with their perception of the central referee's activity by identifying and appraising, in match, the contextual elements in the play on which latter decision-making in duels is based. They estimate the type of play the central referee seeks to produce when making his/her decision. Our results support the relevance of the notion of contextual judgement (Mascarenhas et al., 2005). More, as Unkelbach and Memmert (2008) stated that the central referee calibrates their judgement in 
relation to the players' activity, our results suggest the possibility of a calibration of the assistants' judgement in line with the central referee's one.

By considering, together, the preoccupations and the contextual judgement of the assistant referees, the research enables us to state that the way the assistants are preoccupied with the central referee's activity shapes the manner they can construct their judgement and the way they make their decision on duels. Indeed, in the assistants' preoccupations about the central referee's activity on duels, there appears to be embedded a latent intention to coordinate by making their judgement consistent with his/her across duel cases in the match. The way the assistant will make his/her decision on duels accounts the way he/she has been preoccupied by the central referee activity. This statement can be the base for the development of future research in refereeing and practical perspectives.

\subsection{Future direction for research}

This study showed assistant referees have to manage different tasks apart from judging offside. One can make the hypothesis the assistant referees have to switch from a task of judging offside to the task of adjudicating duels. Therefore, a question arises: how do they switch from one task to another? More, how do assistant referees manage their different preoccupations, and their attention, on the field according to the temporal pressure they have to deal with? These questions can act as the basis for future research.

The cues perceived by the assistants' pertain to their implicit and latent preoccupations with the central referee's decision process. One hypothesis to explain this finding can be that such preoccupations are based on an organisational and social embodied knowledge (AllenCollins, 2009; Pizzera, 2015). As preoccupations should be connected to embodied cognition, the cognitive link between on one hand the referees' knowledge concerning the distribution of tasks among the members of their team, on the other hand the assistants' preoccupations on the 
field and their perception of the central referee's priority, needs to be investigated further. The embodiment of this knowledge in the assistants' cognition has to be studied to understand their perception of the dynamic process of the central referee's decision-making.

As in collective or partnership sports (e.g., basketball; see Bourbousson, Poizat, Saury, \& Sève, 2010 or table tennis; see Poizat, et al., 2012), it is crucial to address how the activities of the referee team members fit together. A number of authors recommend further insight into studying the referees' collective activity (Aragão e Pina et al., 2018; Neville \& Stanton, 2016). Understanding the way assistants' activity fits with the central referee could not solely be achieved by studying their pre-existing and context free knowledge (Mascarenhas et al., 2005). One approach might take into account if the preoccupations of the assistants, based on their perception of the central referee's activity, align with the effective intention of the latter. Research could aim to study the preoccupations of the assistants and central referee, concurrently, in certain moments of the match. Further, within the hierarchically organised refereeing team, the decision of the assistants to intervene in the decision process could depend on the refereeing community's common practice, which should be also investigated.

The link between the assistants' preoccupations and his/her judgement suggests it could be interesting to elicit the preoccupation a central referee has regarding duels. Subsequently, it is pertinent to study if the preoccupations of a central referee evolve during a match and the way these preoccupations evolve. Particularly, it could be hypothesized that an evolution of his/her preoccupations could lead to an evolution in his/her judgement and decision making. Indeed, if the consistency of decisions between the members of refereeing teams is a key point for refereeing performance (Mascarenhas et al., 2005), to better understand the mechanisms favouring this consistency more studies are needed to identify how referees judge events in play according to their contextual judgement. What categories do they construct to judge in the unfolding of the match? How do they construct these categories? 
Besides, future studies should consider the Video Assistant Referee (VAR) Protocol (IFAB, 2018, p. 73) which introduced new team members (VAR and assistant VAR), new prescriptions, and the use of the video tool. That is to say it introduced a new refereeing community's common practice. In this new frame, research could investigate the preoccupations of the central referee, the assistants, the VAR and assistant VAR, and their contextual judgement in situ. Further research is expected to help to create a more complete view of the functioning of the contemporary high level refereeing team in football.

This research and the insights it has provided is significant in that it creates a platform for further work towards understanding the complex decision processes in sports refereeing, which is not limited to the main decision maker or the action, but acknowledges the importance of studying the context and role of each in team dynamics. More, this study shows that investigating the way refereeing team members understand their teammates' preoccupations in game context is a key point to analyse their collective performance (Bourbousson et al., 2011b). Therefore, this research founds the interest of organizing reflective sessions with the referees to help them to construct a shared knowledge about their respective preoccupations, a shared knowledge that could be continuously updated.

\subsection{Training perspectives}

This study gives a complex view of the assistant's activity and of the interactions with the central referee, and how decision making is related to the context to help develop applied training tools for refereeing teams. Eliciting the lived experiences of refereeing team members is a novel way of understanding their performance, but clearly essential because of the implications on training and performance. Indeed, based on our results the assumption can be made that if it were easier to perceive the central referee's decision process for the assistant, particularly when it leads to a non-intervention in the play, this would decrease his/her cognitive 
effort. Making the conditions in and the reasons for which a central referee does or does not intervene in the course of the play more explicit for the assistant in situ would also make it easier for him/her to adjust his/her judgement. Whilst, when it comes to intervening in the refereeing, the assistant is concerned with the acceptable or unacceptable character of the players' behaviour and by the central referee's situation, no training exists for taking this double preoccupation into account. Thus, towards improving the collective performance, it would be pertinent to educate and train the assistants in constructing a contextual judgement based on the central referee's, but also to train the central referee to make apparent, for his/her assistants, the occurrence of the decision processes in relation to his/her contextual judgement. Training sessions to make the significant cues of the referee's decision process more explicit for the assistants could be designed through collaboration within a team.

This kind of training cannot be carried out individually. To be put into practice the central referees must also take part. If revealing what is specific to the meaning of central referees' and assistants' experiences is necessary, this is not, however, easy to do. One particular complication, for instance, is that the assistants' activity fits into socio-cultural and procedural organizational contexts that are quite specific. Indeed, within the refereeing community central referees have a favourable hierarchical position that gives rise to deference by other team members. Thus, developing training techniques to elicit the lived experiences of team members involves setting up protocols to eliminate the inhibiting effect of the social usages and codes when revealing the lived experience. The interview should retranscribe, faithfully, what was experienced in the match. The narrations from experience are not recompositions to satisfy the expectations (in terms of usages and procedures) of the hierarchical superior, i.e., the central referee. Thus, the social conditions favourable to unveiling what assistant experience are still to be created and must be the subject of a specific collective study within the refereeing community. These specificities have to be taken into consideration to construct the conditions 
for unveiling the individual experience within the refereeing collective. By eliciting these conditions, this study sheds light on the complexity of refereeing teams and helps us see a population that is understudied and misunderstood.

\subsection{Limitations}

A methodological limitation is present in relation with the theoretical perspective of our study. While the video the LFP provided remains essential as a trace of activity with which the officials are normally provided, the researcher who conducted the interviews took great care with his/her prompting to navigate the obstacles that may arise when using a video during the self-confrontation interviews: position as spectator rather than actor, tendency to justify instead of describe, or again focusing on the elements to which the actor could not have access in situ. It is still possible to improve the quality of the description of the experience that referees have gone through by using other means. For example, the recording from a head-mounted camera (Rix-Lièvre, 2010) would have given the actor in situ access to other significant elements. However, the production of a video more suitable for the interviews is subject to restrictions related to the context of professional football where the issue of image rights is very sensitive. In the same way, the researchers did not have access to intercommunications of the referees on the field. Having access to such recordings could be a support for conducting the interview based on more vivid information and to enrich the trace of activity the official are confronted about.

Another limitation of this research is about the kind of match investigated. Indeed, the matches studied were only non-decisive games for the championship ranking. If the homogeneity of the investigated matches is a way to support the trustworthiness of our results, it should be interesting to study the assistants' preoccupations in different game contexts (e.g., 
scrutiny, audience, sports stakes) with different features (e.g., technical level) in order to have a better view of the assistant referees' preoccupations at high level in football.

Despite these limitations, this research provides an in-depth exploration of a difficult topic to access (i.e., the assistant referees' experience on the field). The phenomenological approach used here to study referee activity helped to reveal the assistants' latent intention to coordinate with the central referee judgement. This intention is embedded in the assistant referees' preoccupations. Our findings show that assistants have preoccupations about the acceptability of the duels in game and, at the same time, have concerns about the fulfilment of collaborative tasks in respect of the central referee's priority to make decision on duels. Thus, assistants are preoccupied by the occurrence of the decision process, or not, with the central referee about duels. This study presents contextual cues enabling the assistants to appraise whether a decision process happens with the central referee. For the assistant referees, the identification of a decision process occurring with the central referee means the priority of the latter to intervene in the refereeing of duels, while the absence of decision process means the possibility to intervene in this refereeing. Moreover, the findings show how the assistants adjust their way of judging duels to how the central referee judges the previous ones in the game. Given these new findings about assistant referees' effective decision making processes, this research can represent a first step in the potential designing of training programs to support the development of refereeing team performance that could be usefully integrated within the referee community. 


\section{References}

Allen-Collinson, J. (2009). Sporting embodiment: sports studies and the (continuing) promise of phenomenology. Qualitative Research in Sport and Exercise, 1(3), 279-296.

Aragão e Pina, A.J., Passos, A., Araújo, D., \& Maynard, M. T. (2018). Football refereeing: An integrative review. The Psychology of Sport and Exercise, 35, 10-26.

Board, I. F. A. (2012). Laws of the Game 2012/2013. Zurich: Fédération Internationale de Football Association.

Board, I. F. A. (2018). Laws of the Game 2018/2019. Zurich: Fédération Internationale de Football Association.

Bourbousson, J., Poizat, G., Saury, J., \& Sève, C. (2010). Team coordination in basketball: description of the cognitive connections among teammates. Journal of Applied Sport Psychology, 22(2), 150-166.

Bourbousson, J., Poizat, G., Saury, J., \& Sève, C. (2011a). Description of dynamic shared knowledge: an exploratory study during a competitive team sports interaction. Ergonomics, 54(2), 120-138.

Bourbousson, J., Poizat, G., Saury, J., \& Sève, C. (2011b). Team cognition: shared concerns within a basketball team during a match. Le travail humain, 74(1), 59-90.

Bourbousson, J., Poizat, G., Saury, J., \& Sève, C. (2012). Temporal aspects of team cognition: a case study on concerns sharing within basketball. Journal of Applied Sport Psychology, 24(2), 224-241.

Catteeuw, P., Gilis, B., Wagemans, J., \& Helsen, W. (2010a). Offside decision making of assistant referees in the English Premier League: Impact of physical and perceptualcognitive factors on match performance. Journal of Sports Sciences, 28(11), 471-481. 
Catteeuw, P., Gilis, B., Wagemans, J., \& Helsen, W. (2010b). Perceptual-cognitive skills in offside decision making: Expertise and training effects. Journal of Sport and Exercise Psychology, 32(6), 828.

Catteeuw, P., Helsen, W., Gilis, B., \& Wagemans, J. (2009). Decision-making skills, role specificity, and deliberate practice in association football refereeing. Journal of Sports Sciences, 27(11), 1125-1136.

Dale, G. A. (1996). Existential phenomenology: Emphasizing the experience of the athlete in sport psychology research. The Sport Psychologist, 10(4), 307-321.

Dale, G. A. (2000). Distractions and coping strategies of elite decathletes during their most memorable performances. The Sport Psychologist, 14(1), 17-41.

Gouju, J.L., Vermersch, P., \& Bouthier, D. (2007). A psycho-phenomenological approach to sport psychology: The presence of the opponents in hurdle races. Journal of Applied Sport Psychology, 19(2), 173-186.

Luis, V., Canelo, A., Domínguez, F. J., \& Morenas, J. (2018). The influence of refereeing experiences judging offside actions in football. Psychology of Sport and Exercise, 37, $139-145$.

Mascarenhas, R. D., Collins, D., \& Mortimer, P. (2005). The accuracy, agreement and coherence of decision-making in rugby union officials. Journal of Sport Behavior, 28(3), 253-271.

Neville, T. J., \& Stanton, N. (2016). Never blame the umpire - A review of situation awareness models and methods for examining the performance of officials in sport. Ergonomics, 962-975.

Pizzera, A. (2015). The role of embodied cognition in sports officiating. Movement \& Sport Sciences, 87(1), 53-61. 
Plessner, H., \& Haar, T. (2006). Sports performance judgments from social cognitive perspective. Psychology of Sport and Exercise, 7(6), 555-575.

Poizat, G., Bourbousson, J., Saury, J., \& Sève, C. (2009). Analysis of contextual information sharing during table tennis matches: An empirical study on coordination in sports. International Journal of Sport and Exercise Psychology, 7(4), 465-487.

Poizat, G., Bourbousson, J., Saury, J., \& Sève, C. (2012). Understanding team coordination in doubles table tennis: Joint analysis of first-and third-person data. Psychology of Sport and Exercise, 13(5), 630-639.

Poizat, G., Sève, C., \& Saury, J. (2013). Qualitative aspects in performance analysis. Routledge Handbook of Sports Performance Analysis, 309-320.

Put, K., Baldo, M. V., Cravo, A. M., Wagemans, J., \& Helsen, W. F. (2013). Experts in offside decision making learn to compensate for their illusory perceptions. Journal of Sport \& Exercise Psychology, 35(6), 576-584.

Rix, G. (2005). Typologie des actes de jugement de l'arbitre de rugby expérimenté. Movement \& Sport Sciences, $\mathrm{n}^{\circ}$ 56(3), 109-124.

Rix-Lièvre, G. (2010). Différents modes de confrontation à des traces de sa propre activité. Entre convergences et spécificités. Revue d'Anthropologie des Connaissances, 4(2), 357376.

Rix-Lièvre, G., \& Lièvre, P. (2009). Self-confrontation. In A. Millls, G. Durepos \& E. Wiebe (Eds.), Encyclopedia of Case Study Research (Vol. 2, pp. 847-849). Washington: Sage.

Russell, S., Renshaw, I., \& Davids, K. (2019). How interacting constraints shape emergent decision-making of national-level football referees. Qualitative Research in Sport, Exercise and Health, 11, 573-588. 
Schnyder, U., Koedijker, J. M., Kredel, R., \& Hossner, E.-J. (2017). Gaze behaviour in offside decision-making in football. German Journal of Exercise and Sport Research, 47(2), 103109.

Spitz, J., Put, K., Wagemans, J., Williams, A. M., \& Helsen, W. F. (2018). The role of domaingeneric and domain-specific perceptual-cognitive skills in association football referees. Psychology of Sport and Exercise, 34, 47-56.

Theureau, J. (1992). Le cours d'action, analyse sémiologique : essais d'une anthropologie cognitive située. Berne: Peter Lang.

Theureau, J. (2003). Course-of-action analysis and course-of-action centered design. Mahwah, NJ: Laurence Erlbaum Associates.

Theureau, J. (2010). Les entretiens d'autoconfrontation et de remise en situation par les traces matérielles et le programme de recherche « cours d'action ». Revue d'Anthropologie des Connaissances, 4(2), 287-322. doi: 10.3917/rac.010.0287

Unkelbach, C., \& Memmert, D. (2008). Game management, context effect, and calibration: The case of yellow cards in soccer. Journal of Sport \& Exercise Psychology, 30, 95-109.

Vermersch, P. (1999). Introspection as practice. Journal of Consciousness Studies, 6(2-3), 1742.

To cite :

Boyer, S., MacMahon, C., Récopé, M., Rix-Lièvre, G. (2020). The assistant referees' activity in refereeing elite football: Preoccupations when not judging offside. Psychology of Sport and Exercise, 48. $\langle 10.1016 /$ j.psychsport.2020.101662 $\rangle$ https://www.sciencedirect.com/science/article/pii/S1469029218305028?via\%3Dihub 